\title{
The Use of Anisaldehyde Sulfuric Acid as an Alternative Spray Reagent in TLC Analysis Reveals Three Classes of Compounds in the Genus Usnea Adans. (Parmeliaceae, lichenized Ascomycota)
}

Alice da Cruz Lima Gerlach ${ }^{\mathrm{a}, \mathrm{b}}$, Alice Gadea $^{\mathrm{c}}$, Rosa Mara Borges da Silveira ${ }^{\mathrm{b}}$, Philippe Clerc ${ }^{\mathrm{a}}$ \& Françoise Lohézic-le Dévéhat ${ }^{\mathrm{c}}$

${ }^{\text {a}}$ Conservatoire et Jardin botaniques de la Ville de Genève (CJBG), 1 ch. de l'Impératrice, 1292 Chambésy/GE, Switzerland.

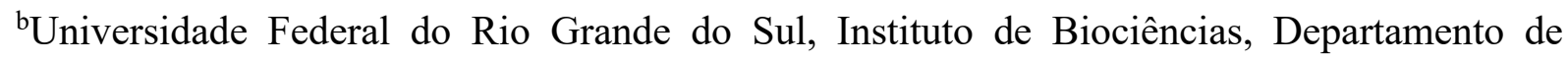
Botânica, Laboratório

de Micologia, Av. Bento Gonçalves, 9500 Campus do Vale, CEP: 91501-970, Porto Alegre/RS, Brazil.

'Univ. Rennes, CNRS, ISCR (Institut des Sciences Chimiques de Rennes) - UMR 6226, F35000 Rennes, France.

Authors to whom correspondence should be addressed; alice_gerlach@yahoo.com.br.

\begin{abstract}
Presence and identity of secondary metabolites are two of the main components of lichen taxonomy. Aromatic compounds formed via the acetyl-polymalonate pathway are the most studied lichen substances. In addition, compounds derived from the mevalonic acid pathway (e.g. terpenes and steroids) are sometimes detected in the medulla. However, their identity and value as diagnostic characters in the genus Usnea are yet poorly understood despite the fact that they were mentioned in several taxonomical papers. We conclude that i) aside from the previously recognized polyphenolic compounds, carbohydrates and steroids are also detected in the medulla of some Usnea species; ii) the use of sulfuric anisaldehyde reagent greatly improves the detection of terpenes, carbohydrates and steroids compared with the sulfuric acid reagent routinely used in thin layer chromatography; iii) among carbohydrates, we detected arabitol and sucrose in the medulla; iv) steroids and terpenes remain unidentified and deserve further investigations.
\end{abstract}

Key words: color tests; thin layer chromatography; chemotaxonomy; secondary metabolites; solvent system.

\section{Introduction}

The identification of secondary metabolites in lichens is useful in the identification of various groups of lichens [1] and in the detection of potential bioactive compounds, e.g., antioxidants and UV filters [2-4]. There is an extensive literature on the chemistry of lichens [5-7] and ca. 1050 lichen [8] compounds were so far described.

The majority of these lichen substances are aromatic compounds formed via the acetylpolymalonate pathway (e.g $\beta$-orcinol-depsidones; $\beta$-orcinol-depsides) and they are produced in various amounts. In the genus Usnea, the dibenzofuran usnic acid is always present in the cortex of the lichen, whereas depsides (e.g. barbatic, diffractaic, thamnolic, squamatic acids), and depsidones (e.g. constictic, fumarprotocetraric, galbinic, norstictic, protocetraric, psoromic, salazinic, stictic acids) are secondary metabolites that are commonly found in the 
medulla. In addition, compounds derived from the mevalonic acid pathway (e.g. terpenoids and steroids) are sometimes detected in the medulla [5]. However, their identity and value as diagnostic characters in the genus Usnea are yet poorly understood. Among the terpenoids, triterpenes (e.g., zeorin) constitute the largest number of compounds isolated from lichens [9]. Their presence in the genus Usnea was mentioned in several systematics studies [10-13]. More recently, [14] detected distinct patterns of terpenoids/steroids in Neotropical species of Usnea, highlighting their importance for species identification in this genus. Despite being frequently mentioned in the literature, terpenoids and steroids in the lichen genus Usnea still remain poorly understood, and their presence is for instance not mentioned by Elix (2014). Unfortunately, they do not show any reaction with the classical color tests used in lichenology $(\mathrm{K}, \mathrm{C}, \mathrm{KC}, \mathrm{P})$ and most of them remain unidentified. Using traditional thin-layer chromatography, accurate detection of terpenoids and steroids is not an easy task: after burning at $100^{\circ} \mathrm{C}$ the TLC plates sprayed with $\mathrm{H}_{2} \mathrm{SO}_{4}$ they appear as various, sometimes barely visible fluorescent spots under long wavelength $(350 \mathrm{~nm})$ with different colors. However the intensity of the spots is fading quite rapidly. Moreover, terpenoids might be however confused with steroids which look very similar [5].

Because accurate detection of these non-aromatic compounds with sulfuric acid is doubtful, we tested another spray reagent called the anisaldehyde sulfuric acid reagent (ANS) instead. The use of this reagent is more informative, when the presence of terpenoids/steroids is suspected because: i) it reveals specific colors for monoterpenes, triterpenes and steroids; ii) a second revelation with thymol sulfurique helps to distinguish them from carbohydrates; iii) the aromatic compounds (e.g. usnic, stictic, salazinic acids) appear with specific colors.

This chemical study is framed within a bigger project of the systematics of the genus Usnea in Brazil (PhD dissertation from the first author). This is the first attempt to test and evaluate the presence of terpenoids/steroids in Brazilian samples of this genus.

\section{Material \& Methods}

\subsection{Lichen Material}

A total of 20 specimens of Usnea malmei Motyka (H18, H19, H20, H21, H22, H52, H54, H55, H58, H59, H60, H61), U. moreliana Motyka (H13, H14, H62, H64) and U. papillata Motyka (H51, H53, H56, H57) (Parmeliaceae) collected in Brazil were analyzed. All these specimens have a $\mathrm{K}-, \mathrm{P}-, \mathrm{C}-, \mathrm{KC}-$ reacting medulla [15].

\subsection{Thin-layer chromatography (TLC)}

A first round of TLC was done at the CJBG (Switzerland) as follows: Secondary compounds were extracted in acetone, boiled and spotted several times (ca. 10) onto Merck silica gel 60 F254 glass plates. Chemical analyses were performed in three routinely used solvent systems: A (toluene/ dioxane/ acetic acid: 180:45:5), B (n-hexane/MTBE/ formic acid-65:40:10) and C (toluene/ acetic acid-200:30) [16,17]. After brief drying, the plates are visualized on UV light $(254 \mathrm{~nm}$ and $365 \mathrm{~nm})$ and are sprayed with a stable solution of anisaldehyde sulfuric reagent (ANS: anisaldehyde/acetic acid/methanol/sulfuric acid-0.5:10:85:5) until wet, and then heated at $110^{\circ} \mathrm{C}$ until development of spots, which were visualized on visible light [18]. We identified when possible the family class according to the colors and retention value (Rf). 
When the presence of other family classes was suspected, fragments of samples were send to the University of Rennes (France), where a second round of TLC was done. First of all, several experimental tests were done with different solvent systems and spray reagents and at different concentrations. For specimens for which the presence of carbohydrates was suspected the experimental tests were done as follows: secondary compounds were extracted in chloroform/acetone/methanol (1/1/1); the extracts obtained were evaporated, weighted (data not showed) and solubilized in bidistilled tetrahydrofuran to obtain $10 \mathrm{mg} / \mathrm{ml}$ solutions (data not showed). The following four controls were used $(10 \mathrm{mg} / \mathrm{ml})$ : arabitol, mannitol, ribitol, and sucrose. Automatic samples application was done for tested samples $(6 \mu 1)$ and controls $(2 \mu \mathrm{l})$ on silica plates (Merck silica gel 60F254) thanks to the CAMAG automatic TLC sampler 3 (ATS3). The plates were then eluted using two solvent systems: i) D (ethyl acetate/formic acid /acetic acid/water -100/11/11/27); ii) E (butanol-1/acetone/water-5/4/1) [16]. Then, plates were sprayed with two different spray reagents: thymol sulfuric acid [18] and anisaldehyde sulfuric acid (anisaldehyde/acetic acid/methanol/sulfuric acid-0.5:10:85:5).

Specimens suspected to contain terpenoids or steroids were tested in the following way: secondary compounds were extracted in chloroform/acetone/methanol $(1 / 1 / 1)$; the extracts obtained were evaporated, weighted (data not showed), and solubilized in the bidistilled tetrahydrofuran to obtain $5 \mathrm{mg} / \mathrm{ml}$ solutions (data not showed). The following controls were used ( $3 \mu \mathrm{L}$ of $5 \mathrm{mg} / \mathrm{ml}$ ): eucalyptol, linalool and $\alpha$-pinene (monoterpenes); hopane-triol, lanosterol and zeorin (triterpenes) as well as cholesterol and ergosterol (steroids). Automatic samples application on silica plates was used for the tested samples $(15 \mu 1)$ and the controls (3 $\mu 1)$. The plates were then eluted using two solvent systems: i) TAE (toluene/ethyl acetate97/3) and ii) G (toluene/ethyl acetate/formic acid-139/83/8) [6]. Finally, the plates were sprayed with anisaldehyde sulfuric acid.

\section{Results}

Some standards (linalool, hopane-triol, ergosterol) were spotted on the TLC plates. When sprayed with ANS reagent, it can be noted that color of monoterpenes was different than for triterpenes and than for steroids. After revelation and heating, monoterpenes, triterpenes and steroids appeared as blue, purple and gray spots, respectively. The color of the spots for carbohydrates/polyols could be confused with those of monoterpenes but they could be easily distinguished thanks to the use of another reagent called sulfuric thymol. In this case, the spots of carbohydrates and polyols appeared as pink \pm red. The aromatic compounds could be revealed under UV at $254 \mathrm{~nm}$ and after spraying ANS, specific colors appeared as purple for usnic acid, red for evernic acid and yellow for stictic acid.

We detected the presence of carbohydrates in all samples of the three species analyzed. Arabitol and sucrose are present in U. malmei, U. moreliana and U. papillata; while mannitol was only found in one specimen of U. malmei. Some steroids and monoterpenes were found in U. malmei and U. papillata while some triterpenes were found in U. moreliana. (Table 1). 
Table 1: Three classes of substances found in U. malmei, U. moreliana and U. papillata. $\mathrm{N}=$ indicate the number of specimens analyzed.

\begin{tabular}{|c|c|c|c|c|c|c|c|}
\hline CLASSES & & \multicolumn{3}{|c|}{ CARBOHYDRATES } & STEROIDS & \multicolumn{2}{c|}{ TERPENES } \\
\hline species & & arabitol & mannitol & sucrose & & monoterpenes & triterpenes \\
\hline U. malmei & $\mathrm{n}=12$ & + & \pm & + & + & + & \\
\hline U. papillata & $\mathrm{n}=4$ & + & & + & + & + & \\
\hline U. moreliana & $\mathrm{n}=4$ & + & & & & & + \\
\hline
\end{tabular}
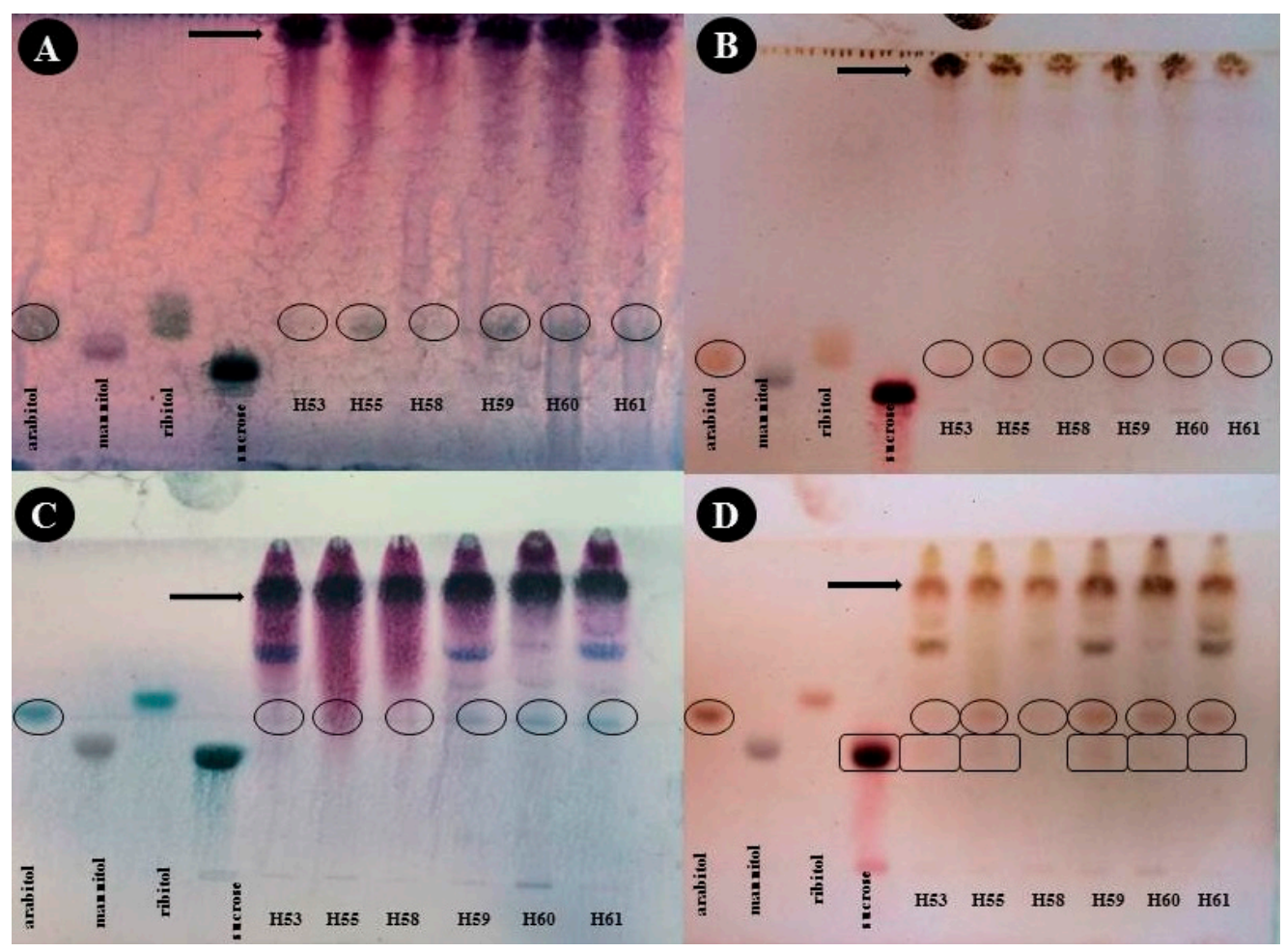

Figures 1A-D: Detection of carbohydrates: TLC analysis of $U$. papillata $(\mathrm{H} 53)$ and $U$. malmei (H55, H58, H59, H60, H61) showing the presence of polyols (arabitol) in four combinations of solvents (D, E)-spray (sulfuric thymol, ANS) systems: A) D-ANS B) D-thymol. C) E-ANS. D) E-thymol. Arrows on the top indicates usnic acid; circles indicate presence of arabitol; squares indicate presence of sucrose. 


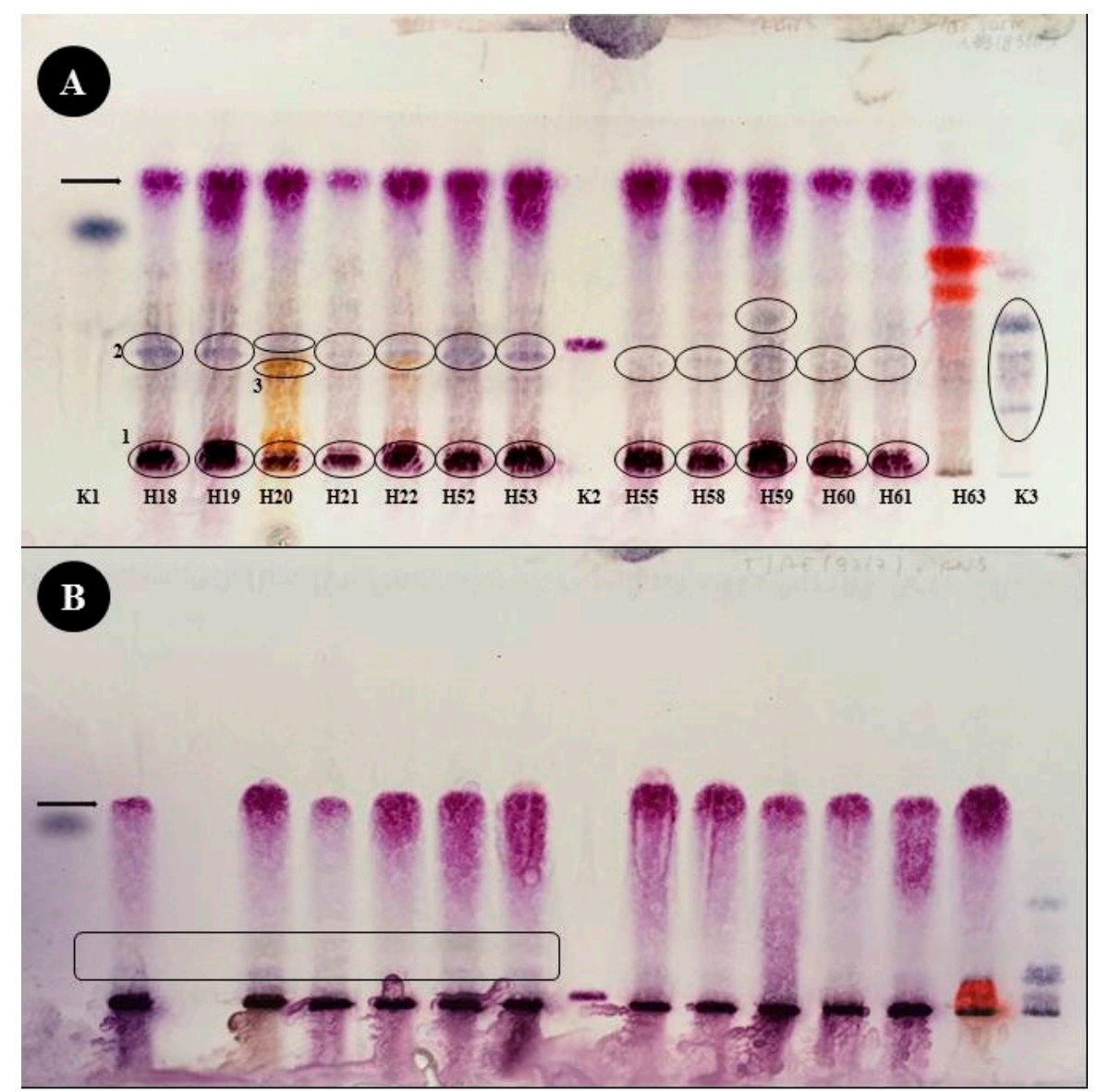

Figures 2A-B: Detection of terpenes and steroids: TLC analysis in two solvents-spray reagent systems of $U$. malmei $(\mathrm{H} 18, \mathrm{H} 19, \mathrm{H} 20, \mathrm{H} 21, \mathrm{H} 22, \mathrm{H} 52, \mathrm{H} 55, \mathrm{H} 58, \mathrm{H} 59)$ and $U$. papillata (H53) with three controls: K1=linalool (monoterpene), K2=hopane-triol (triterpene); $\mathrm{K} 3=$ ergosterol and related compounds (steroids). Arrows on the top indicates usnic acid. A) Plate run in solvent G and sprayed with ANS. Spots surrounded by circles of line 1 indicate the presence of carbohydrates; spots surrounded by circles of line 2 indicate the presence of unidentified steroids (gray spots) and spots surrounded by circles of line 3 indicate the presence of the depsidone stictic acid. B) Plate run in solvent TAE and sprayed with ANS Spots surrounded by a rectangle indicate the presence of unidentified monoterpenes in faint concentration. 


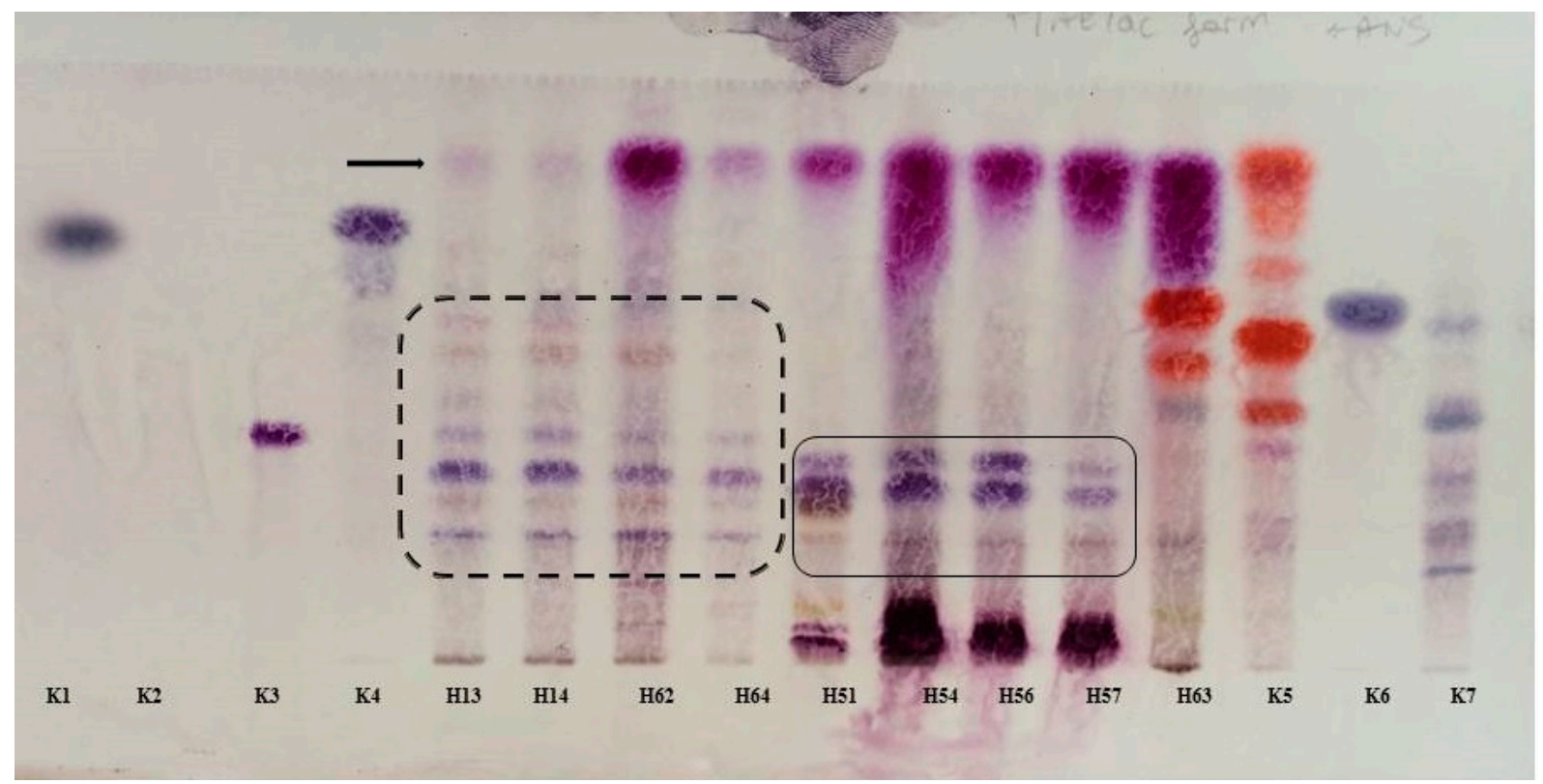

Figure 3: Detection of terpenes and steroids: TLC analysis in the solvent-spray reagent system G-ANS of $U$. moreliana (dashed square) and U. malmei $(\mathrm{H} 54) / U$. papillata $(\mathrm{H} 51$, H56, H57) (solid square) with two distinct chemical patterns: a) unidentified triterpenes in $U$. moreliana and b) steroids in U. malmei/U. papillata (as already showed in Figure 2). The controls were the following: K1=linalool, K2=eucalyptol (monoterpenes); K3=hopane-triol, K4=lanosterol, K5=zeorin (triterpenes, extracted from Evernia prunastri); K6=cholesterol; $\mathrm{K} 7=$ ergosterol and related compounds (steroids). $\mathrm{H} 63=U$. longissima with zeorin. Arrows on the top indicates the presence of usnic acid.

\section{Discussion and conclusions}

Prior to this study, several patterns of substances considered as being triterpenes were detected in Neotropical Usnea species [14] especially specimens showing no reactions with the traditional reagents $(\mathrm{K}, \mathrm{C}$, and $\mathrm{P}$ ) used in lichenology. Our study, however, shows that among these suspected triterpenes, carbohydrates and steroids are also present and that they are even relatively frequent among the tested species. Our study also shows that steroids and terpenes display the same kind of spots in forms and colors in the three solvent TLC system traditionally used by lichenologists. Therefore terpenes and steroids might have been confused in the taxonomical literature so far.

Among the carbohydrates, arabitol and sucrose are relatively frequent in the species studied (Figs., 1A-D) unlike mannitol. These primary metabolites are relatively common in lichens [9]. However, detection of carbohydrates by traditional TLC analysis [16] is difficult because they are often present in faint concentrations. Another difficulty is due to their polar nature which prevents their migration on the silica plates with the solvent systems $(A, B, C)$ traditionally used. For example, the detection of sucrose in the analyzed samples was only possible with the butanol solvent system (Fig. 1D, very weak spots), while solvent D allowed a better separation of arabitol and sucrose. Previously, the presence of ribitol, mannitol and arabitol was already shown in Usnea antarctica and U. fasciata [19].

In the traditional TLC solvent systems, the use of ANS as spray reagent allowed us to detect a strong gray spot at the base of the heated plates in several species of lichens. On the plates sprayed with sulfuric acid $(10 \%)$, routinely used as spray solvent, the same substance 
(carbohydrates) appears only under ultraviolet light $(365 \mathrm{~nm})$ as a fluorescent spot after charring. It was probably due to its fluorescence that this substance was misinterpreted as a terpene by $[14$, Fig. 2 , as U. malmei/U. papillata]. The same substance was not detected by the same authors in $U$. moreliana (Fig. 2 as $U$. rubricornuta). Using the alternative spray solvent ANS, we were however able to show the presence of this sugar in this species (data not showed, very weak).

Besides carbohydrates, two other classes were found: steroids (Fig. 2A; gray spots) and terpenes: monoterpenes (Fig. 2B, very faint) and triterpenes (Fig. 3; violet spots). We found a high diversity of medullary compounds related to steroids/terpenoids, none of which corresponding to the controls used in this study. Both terpenoids and steroids displayed very similar pattern visualized as several gray-violet spots on the middle of the plates. Despite our efforts, these compounds remained unidentified and deserve further investigations. For instance, Usnea moreliana exhibited a typical pattern of unidentified triterpenes in the medulla (Fig. 3), also found by [14, Fig. 2, as U. rubricornuta) diagnostic for this species.

Terpenes are common in various groups of lichens and were used for instance in the taxonomy of Nephroma [20] and Peltigera where 35 distinct terpenes were recognized [21]. Terpenes were also identified and used in the taxonomy of Physcia [22].

In Usnea, however, although widely mentioned in the literature, the identity of terpenes remains poorly known. We found only reference to zeorin [12,23-26] and four other terpenes in Usnea longissima Ach. [26]. The presence and the nature of the terpenoids in this genus, therefore, deserve further investigations and using combination of high pressure liquid chromatography (HPLC) with an evaporative light scattering detector (ELSD) and mass spectrometer (MS) is in progress to identify them.

Finally, this study reveals the presence of two other classes of medullary compounds besides the terpenes widely mentioned in the literature. A few carbohydrates were identified but terpenes and steroids remain unidentified and deserve further investigations. Spraying the plates with ANS before charring improves the visualization of these classes of substances not easily seen with traditional methods. We therefore strongly recommend the use of the ANS spraying system as routine analysis aiming at detecting for taxonomy useful patterns especially in specimens with $\mathrm{K}-, \mathrm{C}$ - and $\mathrm{P}$ - medullary reactions.

Acknowledgments: This work was supported by the Conservatoire et Jardin botaniques de la Ville de Genève (CJBG) and the Université de Rennes. The first author acknowledges financial support from CNPq (Brazil) and by Swiss Government Excellence Scholarship. We thank Manuela Dal Forno for her review of the English. The authors are also indebted to Joël Boustie for giving access to the laboratory facilities.

\section{Reference}

[1] Lumbsch, H.T. Analysis of phenolic products in lichens for identification and taxonomic. In: Protocols in Lichenology. Culturing, Biochemistry, Ecophysiology and Use in Biomonitoring. Eds. Kranner, I., Beckett, R.P., Varma, A.K. Springer-Verlag, Berlin, Heidelberg, 2002, pp. 281-295.

[2] Huneck, S.; Yoshimura, I.. Identification of Lichen Substances. Springer-Verlag, Berlin, Heidelberg. 1996, 493 pp. 
[3] Lohézic-Le Dévéhat, F.; Tomasi, S. ; Elix, J.A.; Bernard, A.; Rouaud, I.; Uriac, P.; Boustie, J. Stictic acid derivatives from the lichen Usnea articulata and their antioxidant activities. J. Nat. Prod., 2007, 70, 1218-1220.

[4] Lohézic-Le Dévéhat, F.; Legouin, B.; Couteau, C. ; Boustie, J. ; Coiffard, L. Lichenic extracts and metabolites as UV filters. $J$ Photochem. Photobio B, 2013, 120, 17-28.

[5] Elix, J.A. A catalogue of standardized chromatographic data and biosynthetic relationships for lichen substances, 3rd edn. 2014, 323 pp., Published by the author, Canberra. http://www.anbg.gov.au/abrs/lichenlist/Chem\%20Cat\%203.pdf

[6] Orange, A.; James, P.W.; White, F.J. Microchemical Methods for the Identification of Lichens. British Lichen Society. 2001, 101 pp.

[7] Huneck, S.; Yoshimura, I. Identification of Lichen Substances. Springer-Verlag, Berlin, Heidelberg. 1996, 493 pp.

[8] Stocker-Wörgötter, E. Metabolic diversity of lichen-forming ascomycetous fungi: culturing, polyketide and shikimate metabolite production, and PKS genes. Nat. Prod. Rep., 2008, 25, 188-200.

[9] Honda, N.K.; Vilegas, W.. A química dos liquens. Química Nova, 1998, 21(6), 110-125.

[10] Halonen, P. Studies on the lichen genus Usnea in East Fennoscandia and Pacific North America. 2000, $\mathrm{PhD}$ thesis. Oulu: University of Oulu.

[11] Halonen, P.; Clerc, P.; Goward, T.; Brodo, I.M.; Wulff, K. Synopsis of the genus Usnea (lichenized Ascomycetes) in British Columbia, Canada. Bryologist 1998, 101, 36-60

[12] Ohmura, Y. Taxonomic study of the genus Usnea (lichenized Ascomycetes) in Japan and Taiwan. J. Hattori Bot. Lab., 2001, 90, 1-96.

[13] Herrera-Campos, M.A.; Clerc, P.; Nash, T.H. III. Pendulous species of Usnea from the temperate forests in Mexico. Bryologist, 1998, 101, 303-329.

[14] Truong, C.; Rodriguez, J.M.; Clerc, P. Pendulous Usnea species (Parmeliaceae, lichenized Ascomycota) in tropical South America and the Galapagos. Lichenologist 2013, 45, 505-543.

[15] Hale, M.E, Jr. How to Know the Lichens. 2nd. edn. Wm. C. Brown Co., Dubuque, Iowa. 1979, $246 \mathrm{pp}$.

[16] Culberson, C.F.; Ammann, K. Standardmethode zur Dünnschichtchromatographie von Flechtensubstanzen. Herzogia, 1979, 5, 1-24.

[17] Culberson, C.F.; Johnson, A. Substitution of methyl tert-butyl ether for diethyl ether in the standardized thin-layer chromatographic method for lichen products. J. Chromatogr. 1982, 238, 483-487.

[18] Le Pogam, P.; Herbette, G.; Boustie, J.. Analysis of Lichen Metabolites, a Variety of Approaches. In: Recent Advances in Lichenology. Eds. Upreti, D.K.; Divakar, P.K.; Shukla, V.; Bajpai, R. Springer India, 2015, pp. 229-261.

[19] Tearle, P.V. Cryptogamic carbohydrate release and microbial response during spring freeze-thaw cycles in antarctic fellfield fines. Soil Biol. Biochem. 1987, 19(4): 381-390.

[20] James, P.W.; White F.J. Studies on the genus Nephroma I. The European and Macaronesian species. Lichenologist, 1987, 19(3), 215-268.

[21] Miadlikowska, J.; Lutzoni, F. Phylogenetic revision of the genus Peltigera (LichenForming Ascomycota) based on morphological, chemical, and large subunit nuclear ribosomal DNA Data. Int. J. Plant Sci. 2000, 161(6), 925-958. 
[22] Elix, J.A.; Corush, J.; Lumbsch, H.T. Triterpene chemosyndromes and subtle morphological characters characterize lineages in the Physcia aipolia group in Australia (Ascomycota). Syst. Biodivers. 2009, 7(4), 479-487.

http://dx.doi.org/10.1017/S1477200009990223

[23] Rogers, R.W.; Stevens, G.N. The Usnea baileyi complex (Parmeliaceae, Lichenised Ascomycetes) in Australia. Aust. Syst. Bot., 1988, 1, 355-361.

[24] Kaa, S.; Sangvichien, E.; Boonpragob, K.; Tee, D.C. Secondary metabolic profiling and antibacterial activities of different species of Usnea collected in Northern Philippines. Mycosphere 2013, Doi 10.5943/mycosphere/4/2/10

[25] Truong, C.; Clerc, P. Eumitrioid Usnea species (Parmeliaceae, lichenized Ascomycota) in tropical South America and the Galapagos. Lichenologist 2013, 45, 383-395.

[26] Prateeksha, B.S.P.; Bajpai, R.; Jadaun, V.; Kumar, J.; Kumar, S.; Upreti, D.K.; Singh, B.R.; Nayaka, S.; Joshid, Y.; Singh, B.N. The genus Usnea: a potent phytomedicine with multifarious ethnobotany, phytochemistry and pharmacology. RSC Adv. 2016, 6, 2167221696. 